\title{
Introducing Programming and Digital Competence in Swedish K- 9 Education
}

Fredrik Heintz, Linda Mannila, Lars-Åke Nordén, Parnes Peter and Regnell Björn

\section{Conference paper}

N.B.: When citing this work, cite the original article.

Part of: Informatics in Schools: Focus on Learning Programming: 1oth International Conference on Informatics in Schools: Situation, Evolution, and Perspectives, ISSEP 2017, Helsinki, Finland, November 13-15, 2017, Proceedings, Valentina Dagienè and Arto Hellas (eds), 2017, pp. 117-128. ISBN: 9783319714820 (print) and 9783319714837 (online)

Lecture Notes in Computer Science, 0302-9743, Volume 10696

DOI: https://doi.org/10.1007/978-3-319-7148.3-7_10

Copyright:

Available at: Linköping University Institutional Repository (DiVA)

http://urn.kb.se/resolve?urn=urn:nbn:se:liu:diva-141852 


\title{
Introducing Programming and Digital Competence in Swedish K-9 Education
}

\author{
Fredrik Heintz, Linda Mannila, Lars-Åke Nordén, Peter Parnes, and Björn \\ Regnell \\ Linköping University, Linköping University, Uppsala University, Luleå University of \\ Technology, Lund University, Sweden
}

\begin{abstract}
The role of computer science and IT in Swedish schools has varied throughout the years. In fall 2014, the Swedish government gave the National Agency for Education (Skolverket) the task of preparing a proposal for K-9 education on how to better address the competences required in a digitalized society. In June 2016, Skolverket handed over a proposal introducing digital competence and programming as interdisciplinary traits, also providing explicit formulations in subjects such as mathematics (programming, algorithms and problem-solving), technology (controlling physical artifacts) and social sciences (fostering aware and critical citizens in a digital society). In March 2017, the government approved the new curriculum, which needs to be implemented by fall 2018 at the latest. We present the new K-9 curriculum and put it in a historical context. We also describe and analyze the process of developing the revised curriculum, and discuss some initiatives for how to implement the changes.
\end{abstract}

\section{Introduction}

In recent years, we have witnessed an active discussion surrounding the role of programming and computer science (CS) for everyone (see e.g., $[9,16])$. As a result, an increasing number of countries have introduced or are in the process of introducing CS in their school curriculum. For instance, in Europe, the majority of countries (17 out of 21) taking part in a survey conducted by the European Schoolnet in 2015 reported doing so [1]. The way in which this is accomplished varies. Some countries focus on $\mathrm{K}-12$ as a whole, whereas others primarily address either K-9 or grades 10-12. Some countries have introduced CS as a subject of its own (e.g. Computing in England [3]) while others have decided to integrate it with other subjects, by for instance making programming an interdisciplinary element throughout the curriculum (e.g. Finland [6]). A review of models for introducing aspects of CS in K-12 education is presented in, for instance, [7].

The role of CS and information technology (IT) in school curricula has - in general - varied over the years, placing focus on different areas, ranging from using technology as a tool to learning how the computer works and how to use it to create programs. This has also been the case in Sweden. In this paper, we present a historical overview of technology and CS in Swedish K-12 curricula, leading 
up to a revised curriculum being accepted in March 2017, introducing digital competence and programming as interdisciplinary traits, also providing explicit formulations in subjects such as mathematics (programming, algorithms, and problem-solving), technology (controlling physical artifacts) and social studies (fostering aware and critical citizens in a digital society). We describe and analyze the process of developing the new curriculum, and discuss some initiatives for how to implement the changes.

\section{History of IT and CS in Swedish Schools}

Already in the early 1970s, the Swedish government gave the agency responsible for school curricula the task of investigating the possibilities of starting to teach computer technology in Swedish schools. In the curriculum from 1980 (Lgr 80), CS (datalära) was introduced in mathematics in grades 7-9, with a clear focus on letting students learn about computers. Computers were also mentioned in natural and social studies, with emphasis being on understanding the consequences the rapid development has on both individuals and the society as a whole.

All students need to be taught about the use of computers in our society and about the fast development in the field. In particular, students should realize that the computer is a technological tool, being controlled by humans. (Lgr 80, p. 107, free translation from Swedish)

National programs were initiated to prepare students for living in a world where computers were thought to play a significant role. The UIDA programme (Utbildning infr datorsamhället, Education for the computer society) aimed at giving all students in grades 7-9 "such knowledge that they can, want and dare to influence the use of computers in the society" [10, p. 104]. In the mid 1980s a specialized school computer called COMPIS (COMPuter in Shool) was introduced. It rather quickly lost ground to the PC due to its limited functionality.

In the 1990s, computers became easier to use, the number of existing software grew and the user interface became more easily approachable. In addition, teachers rarely had sufficient competence for teaching CS, in particular programming. As a consequence, focus was switched from CS towards digital literacy, i.e. how to use applications, tools and computers. Instead of learning about computers, the curriculum from 1994 (Lpo 94) focused on helping students learn with computers. At the same time, there was a number of initiatives introducing computers in school, for instance the DIG (Datorn i grundskolan, the computer in school) and DOS (Datorn och skolan, the computer and school) projects. Access to computers at homes also rose during the same time as the Home-PCreform was introduced. This reform made it possible for employees to acquire a computer from their employer against a gross deduction. In the early 2000s, initiatives such as ITiS (IT i Skolan, IT at school) and PIM (Praktisk IT- och Mediekompetens, practical IT and media competence) aimed at helping teachers find good ways of using computers at school. The most recent curriculum reform took place in 2011 (Lgr 11). For a more detailed historical overview of computers and programming in Swedish education see [11]. 


\section{Reintroducing CS in Swedish Basic Education}

The Swedish school debate has, in recent years, circled around poor PISA results, difficulties in providing all children and youth with equal opportunities, and about modernizing the curriculum to meet changing job market requirements. As "programmer" is one of the most common jobs in Stockholm, and the need for software professionals is estimated to increase heavily both in Sweden and internationally, some have argued that the educational system should teach programming to prepare young people for these jobs. Others, the authors of this paper included, believe that school should offer all students general preparation for any kind of work, and have therefore argued for digital competence as part of all-round-learning, including computational thinking as a set of general problem-solving skill useful for all in the spirit of Jeannette Wing [17].

In 2012, the Swedish government established the Digitalization Committee (Digitaliseringskommisionen) with the task of providing guidelines for the future of work related to digitalization in Sweden. One of the committee's reports [4] highlights the need for the school system to put larger focus on digital competence. The report explicitly points out the need for including programming in the curriculum as part of existing subjects.

As a result of the discussion around schools, programming and CS as part of all-round learning, persons representing school, universities and industry engaged in voluntary initiatives to help bridge the lack of CS in Swedish basic education. Teacherhack [14] is a nonprofit organization aiming at inspiring "teachers to hack the current curriculum ( Lgr 11) to include the essential skills that students need in a digital world". The Teacherhack website provides reviews of all subjects in Lgr 11 with practical advice on how the current texts can be interpreted in order to allow for a more active inclusion of content and practices related to CS, programming and the Internet, as well as to security and integrity issues. Extracurricular activities such as CoderDojos, code camps, after-school clubs and makerspace activities are organized to give children and youth access to informal learning opportunities. Teachers throughout the country are experimenting and sharing experiences from introducing programming in different subjects, ranging from languages to handicraft and music. Heintz et. al. [8] present an overview of ongoing activities related to CS and computational thinking in Sweden, highlighting several projects that show how one can introduce CS already within the current curriculum.

In September 2015, the Swedish government gave the National Agency for Education (Skolverket) the task of presenting a national IT strategy for the Swedish school system. As one part of this work Skolverket was to update the curricula for primary $(\mathrm{K}-9)$ and upper secondary education (grades 10-12). The government explicitly stated that the curriculum should 1) strengthen students' digital competence and 2) introduce programming at the K-9 level.

Vinnova, Sweden's innovation agency, has also funded a number of research projects related to the digitalization of school. One of these, the Trippel Helix Project (www.trippelhelix.se), aims at getting school, industry and academia, with regional backing, to together formulate a common concrete and achievable 
action plan. The plan should be coordinated with the IT-strategy of the Swedish National Agency for Education, pushing intellectual and operational changes in the school of the future, based on the possibilities and knowledge demands created by the digitalization.

\section{Process}

The directive from the government to Skolverket called for involving relevant agencies, organizations and groups in the process. Skolverket formed several reference groups, including one in CS education research. The authors of this paper have participated in the process from two different perspectives; as a reference group in CS education research and as part of the Trippel Helix project.

In the first stage, the researchers in the CS education reference group were asked to review the current curriculum for grades 1-9 and suggest changes and additions supporting the introduction of programming and digital competence. The reference group met with Skolverket in December 2015 and presented their input. All researchers suggested that digital competence and programming should be integrated in as many existing subjects as possibly (preferably all of them), and not as a subject of its own. The role of CS was also emphasized, rather than focus on programming which is seen as a particular skill within the broader subject of CS.

Within the Trippel Helix project, representatives from industry, academia and the school system work together collectively on supporting the digitalization of education. During January and February 2016, three workshops were arranged in different parts of Sweden (Stockholm, Gothenburg and Lund) to collect input to the National IT Strategy and the new curriculum, both K-9 and 10-12. The outcome of these workshops was handed as input to Skolverket's ongoing work.

In early March 2016, a first draft including suggested curriculum changes was sent out to different interest groups, with a request for feedback. Many of the additions suggested by the CS education group were included in the draft, but quite a few had also been left out. A few weeks later the first public draft was published on the web. The authors provided feedback on the public draft from a CS education perspective. In late April, the final public draft for a new curriculum was published for anyone to give feedback on, with no explicit request for feedback from the reference groups. In June 2016, Skolverket handed over a proposal for revising the current curriculum to the government.

\section{Revised Curriculum for Grades 1-9}

In March 2017, the Swedish government accepted Skolverket's proposal [15] introducing a new general section on the importance of digital competence. The new curriculum is mandatory from fall 2018, but schools and teachers are free to start following it earlier if they want to. 
Skolverket acknowledges that the meaning of digital competence changes over time due to changes in society, technology and available services [12]. Skolverket's definition is based on the DigComp framework developed by the European commission [5] and the work by Digitaliseringskommissionen [4]. In the Swedish curriculum, digital competence includes four aspects: 1) understanding how the digitalization affects individuals and society, 2) understanding and knowing how to use digital tools and media, 3) critical and responsible usage of digital tools and resources, and 4) being able to solve problems and implement ideas in practice. In a supplemental material [12], Skolverket stresses that the responsibility of helping students develop their digital competence is a responsibility for all subjects.

Programming is considered part of this definition. The supplemental material clarifies that focus is not on coding skills, but on programming as a pedagogical tool and problem-solving process including many phases. Programming should also be seen in a wider context, including "creation, controlling and regulating, simulations and democratic dimensions" [12, p. 10, freely translated]. Skolverket emphasizes the importance of seeing programming in this wider perspective both as a basis for teaching and as part of all four aspects of digital competence.

This provides the general setting for the revised curriculum and the four aspects of digital competence can be found throughout the curriculum, both in general parts and in the course plans for specific subjects. In the following, we outline the most important changes made to the content of three subjects mathematics, technology and social studies - to address various aspects of digital competence. The outline also shows the progression within different subjects, based on the three curriculum levels (grades 1-3, grades 4-6, and grades 7-9). The Swedish curriculum categorizes content for each subject under a number of headlines in order to make the document more readable.

Programming is introduced mainly as part of the mathematics curriculum under the topics "Algebra" and "Problem-solving". The progression is as follows:

- Grades 1-3: How unambiguous step-wise instructions can be constructed, described and followed as a basis for programming. The use of symbols for step-wise instructions.

- Grades 4-6: How algorithms can be created and used for programming. Programming in visual programming environments.

- Grades 7-9: How algorithms can be created and used for programming. Programming in different programming environments. How algorithms can be created, tested and iteratively improved when using programming for mathematical problem-solving.

The subject technology was introduced in the Swedish curriculum in 1994, with the goal of helping students develop knowledge and skills needed for orienting and acting in a technology intensive world. The revision puts increased attention on digital technology and the need for developing an understanding for how computers and networks work. The changes are made under three main topics. For the topic "Technical solutions", the revisions focus on understanding aspects: 
- Grades 1-3: What computers are used for and some fundamental devices for input, output and storage of information, for instance, keyboard, monitor and hard drive. Some common artifacts that are controlled by computers.

- Grades 4-6: Some of the components and functions of a computer, for instance processor and working memory. How computers are controlled by programs and can be connected through networks.

- Grades 7-9: IT solutions for exchanging information, such as computers, Internet, and mobile phones. Technical solutions that use electronics and how these are programmed.

Under the topic "Development of technical solutions", focus is placed on programming as a means for controlling and creating technology.

- Grades 1-3: Controlling artifacts through programming.

- Grades 4-6: Controlling own constructions or other artifacts through programming.

- Grades 7-9: Controlling and regulating own constructions, for instance using programming. How digital tools can support the development of technical solutions, for instance making drawings and doing simulations.

The related content under the topic "Technology, man, society and the environment" focuses on safety and integrity aspects:

- Grade 1-3: Safety when using technology, for instance when handling electricity and using Internet services.

- Grade 4-6: Safety when using technology, for instance when transmitting information digitally. How technology is part of and changes the basic conditions for different professions within all areas of society.

- Grade 7-9: Internet and other global technical systems, their benefits, risks, and limitations. Safety when using technology, for instance storing and protecting data.

In social studies, the changes focus on digital competence, understanding the influence that the digital transformation has on us as both individuals and a society, and helping students become critical and responsible citizens in today's digitalized society. For the early grades (1-3), the previous texts on norms and rules as well as evaluating sources have been expanded to also include digital contexts. For grades 7-9, the main revisions concern two topics, with the progression for the topic "Information and Communication" being the following:

- Grades 4-6: How to act responsibly regarding the use of digital and other media from a social, ethical, and legal perspective.

- Grades 7-9: The valuation of news and how it can be influenced by people's views of the world. How individuals and groups are portrayed, for example based on gender and ethnicity as well as how information in digital media is controlled through hidden programming. The opportunities and risks associated with Internet and digital communication through electronic media as well as how to act responsibly regarding the use of digital and other media from a social, ethical, and legal perspective. 
Under "Societal resources and distribution" the progression is as follows:

- Grades 4-6: The importance of digitalization for the individual, for example in the form of improved possibilities for communication and e-commerce.

- Grades 7-9: The importance of digitalization for the development of society in different areas, for example influence on the job market and infrastructure as well as changed attitudes and values.

In addition to the quite notable revisions made in these subjects, other subjects are also affected by the revision. Concrete examples are for instance the introduction of modeling and simulations in natural sciences, extending the range of materials and techniques to be used in crafts and emphasizing responsible communication in languages. In summary, digital competence is visible throughout the new curriculum, both in the general parts and in specific subjects.

\section{Implementation}

Revising the curriculum is only the first step, the next challenge is to implement these changes in practice. There are more than 200000 teachers in Sweden and the need for in-service professional development is huge. The important question is: How can teachers throughout the country be supported in teaching programming and digital competence in their subjects?

Although the situation when introducing Computing in the curriculum in England was somewhat different (own subject, ICT teachers already available at schools), many of the challenges are the same. While ICT teachers were proficient in teaching how to use technology, most of them had no prior experience in programming or other topics focusing on understanding the technology. Hence, one can expect to learn from their experiences in Sweden as well.

In England, companies such as Microsoft and BBC have supported the introduction of Computing. The support organization Computing at School (CAS) has helped build a network of teachers, who teach their peers, and a community supporting teachers through local hubs, material distribution, and professional development. It may seem as if teachers in England have received sufficient support. The transition to Computing has, nevertheless, not been unproblematic. After the first year of having Computing, two main challenges were found [13]: teachers' limited programming skills and a lack of self-esteem for teaching the new subject. Even though many of the teachers had taught ICT previously, most of them had no prior experience in programming and CS. The formal professional development offered has not been sufficient and many teachers have felt the need to learn more on their own. Before the first school year of teaching Computing, $60 \%$ of all teachers felt they did not know enough to teach the new subject [2]. After the first term, almost half of the students felt teachers needed more training and over $40 \%$ of the students said that they had helped their teachers. Over $80 \%$ of teachers called for more training, in particular in programming.

In Sweden, Skolverket has developed online course modules to support teachers in learning to teach the new content. These modules include, for instance, 
school leadership in a digitalized world, programming as an interdisciplinary approach, and programming in mathematics and technology. These modules can be taken at any time, but the recommendation is for colleagues to get together and take the course at the same time, forming collegial learning groups where teachers can learn from each other and share experiences and ideas. In addition, Skolverket arranges conferences throughout the country aimed at showing teachers what the changes mean in practice. Moreover, the supplemental material describes what the new content entails and how it fits in the school context.

The universities are also in the process of slowly renewing the teacher training to meet the new requirements. Currently, the teacher training programs do not include any mandatory courses in digital competence or programming. Skolverket does not control university education, and can hence not place any requirements on them. The universities do however need to educate teachers in the competences and skills required by the current curriculum. Many universities are, for instance, planning courses on different aspects of digital competence, including programming, aimed at both pre- and in-service teachers. One challenge is that the process of introducing new courses often have lead-times of 18-24 months. At least one university (Uppsala) has chosen to compensate for these lead-times and pre-service teachers' lack of training in digital competence and programming by offering complementary education in the form of coding camps offered to students that are graduating within the next 24 months. Other organizations, both public and private, also take an active role in making the transition as smooth as possible. For instance, a school in Stockholm (rstaskolan) has started a portal of courses, which are freely available to anyone and help teachers learn the basics of programming in different languages in a concrete manner. Swedish national TV produces TV series, showing how to introduce programming to children. Funding is offered for development and research projects, aimed at finding good ways to teach the new content, hence contributing to a set of best practices. Dedicated social media groups gather teachers from all over the country to share ideas and experience as well as answer each other's questions. Regular digichats are organized to provide an informal channel to discuss digitalization, digital competence, and school.

The proposed IT strategy, which is not approved by the government yet, also discusses important issues related to the new curriculum. For instance, the need for updating the IT infrastructure. This includes access both to stable and open Wi-Fi networks and computing devices (each teacher should have her own device within two years and each student should have their own device within three years). The IT strategy also discusses the need for computing devices to be open for teachers and students to test and install their own software. This is very important as in several cases in Sweden, the power of selecting learning material has moved away from teachers and schools to their IT-departments. That is, the format of the tool (from pen and paper to a digital device) dictates who should decide on which learning material to use in the classroom. There are examples where this process has led to computers and networks being totally locked down with committees being the deciding body on which tools to allow. 
The IT strategy also requires principals and other school leaders and administrative personnel to have an understanding of the issues involved. Principals play a particularly important role in the implementation process as they must promote and support their teachers in their teaching development efforts.

\section{Discussion}

In this section, we discuss the revisions from several perspectives including subject integration, bootstrapping, ambition, and equal opportunities.

Own subject or integrated approach. As noted above there seems to be two ways in which countries are introducing CS or programming in their curriculum. England provides a prime example of where the content has been packed into one subject (Computing). In other countries, Sweden included, this has not been the route taken; instead programming and CS content has been integrated in existing subjects. Introducing a subject of its own makes practical questions related to who will teach the content unnecessary - dedicated Computing teachers teach the subject Computing in England. The rationale for choosing an integrated approach is manifold: 1) lack of space for introducing a new subject in the curriculum, 2) letting students see and experience the use of programming in different subjects (e.g. for raising interest among previously underrepresented groups), and 3) introducing computational thinking, providing students a framework for how they can work together with the computer to solve increasingly complex problems. There are also practical considerations such as the negative experience of introducing the subject Technology in 1994 which needed about 20 years to find its place, as well as the need for creating a teacher accreditation for a new subject, which would take years to settle. In addition, as Sweden is only revising the current curriculum, not creating a new one, introducing a totally new subject would most likely not have been feasible.

Bootstrapping problems. The introduction of a new curriculum that spans grade 1 to grade 9 naturally has to take into account a phased ramp up where the progression is continuously adapted to the penetration of the curriculum in terms of number of years of prior knowledge to build on. There is hence a notable challenge in how to bootstrap the introduction of the revised curriculum. Students in all grades (1-9) will need to start with the basics to be able to take on more advanced topics later on. This requires teachers to take the curriculum requirements for lower grade levels into account when designing the progression for their current student group. A particular challenge arises in the intersection between school levels, for instance, when students move from grade 6 to grade 7 . At this point many students move to another school, resulting in teachers having a group of students, whose background in the new content can vary greatly depending on which school they have attended and what teachers they have had. The progression in the revised curriculum is expressed as if the curriculum has already reached a steady state. This leaves local authorities throughout the country with the responsibility of implementing the changes and solving the bootstrapping challenge. 
Too much or too little. As always when discussing changes and renewal processes, critical voices are heard. Whereas some seem to think that schools should not focus too much on digitalization aspects but pay more attention to basic - and traditional - skills such as reading, writing, and calculating, others think that the revisions are too vague and not bold enough. Developing steering documents for education is difficult, as they should stay relevant for many years. The situation is particularly difficult for a rapidly moving area such as information technology. It is therefore crucial to focus on key principles and ideas instead of detailed instructions and buzzwords. Describing content and learning objectives in general terms is the only way to guarantee that a curriculum will not be outdated after a short period of time. This also holds for the revisions, which are written quite broadly, leaving ample room for interpretation. However, these descriptions are often too vague for teachers and school leaders who are to implement the curriculum in practice. There is hence a need for additional material providing concrete examples of how the curricula requirements can be implemented in the classroom. Such additional material can be updated and expanded on in a fast and agile manner, compared to the curriculum. Experience and knowledge acquired from the large number of active projects and collaboration initiatives between schools, municipalities, industry, and universities will be of great importance when implementing the changes at national level. Material developed and lessons learned abroad can also help avoid reinventing the wheel.

Equal opportunities and broadened participation. In the beginning, the lack of detail in the curriculum can, however, be positive, as this leaves teachers with a more easily approachable task. Instead of having detailed requirements, they can do what they feel is enough and cover more content at more advanced levels as they have learned more and become more experienced themselves. On the other hand, this also introduces the obvious risk of teachers not raising their ambition level as time goes by. Another risk is that all teachers will not see the new content as their responsibility, but rather as part of some other teacher's duties. A challenge for the future is hence to get everyone to do enough - this is a crucial aspect if we are to arrive at a school system providing equal opportunities to all students regardless of where in the country they live and who they happen to have as their teacher. The role of principals and school leaders thus need to be stressed - it is their job to make sure that all teachers are able to provide children and youth with the skills and content listed in the curriculum. One important, but implicit, goal in the revised curriculum is to broaden the participation in CS related study programs and jobs. This has also been one of the important aspects that the authors of this paper raised in our discussions with Skolverket. This is also one of the reasons why we argued for integrating programming into as many subjects as possible, in particular also in aesthetic subjects such as arts, handicraft, and music. The revisions, however, mainly introduce programming in mathematics and technology, two subjects that can be seen as the traditional and expected choice. We therefore see a risk that the revised curriculum will not broaden participation as much as one would have liked. At the same time, programming is introduced from grade $1 \mathrm{so} \mathrm{ev-}$ 
eryone will get exposed to programming from an early age, which may have a positive influence on participation.

The role of Computer Science. The revised curriculum does not mention computer science or any other synonym to the word. Rather, the focus is on digital competence and programming. We believe this is very unfortunate, as CS is the foundation for programming and includes much more than only programming. This is further exacerbated by introducing programming mainly for mathematical problem-solving and controlling technical artifacts. The international trend, especially in the US, is to broaden the perspective and move the focus from programming to the broader subject of computer science. This is also related to the desire to broaden the participation as discussed above. To engage and interest a broader group, the content needs to be broadened to speak to this larger group. Further, CS is an academic subject, which programming is not. To us introducing programming without CS is like introducing physical experiments without introducing physics. We see upgrading CS to a status of accepted general knowledge, similar to for instance mathematics and physics, as an important goal.

\section{Conclusions}

Educational systems all over the world are being updated to reflect the possibilities and challenges in the digitalized society. One part of these changes is related to the inclusion of programming and computer science content in basic education. The ways in which this is accomplished vary, and the Swedish revisions are well in line with other countries, where the content is integrated in other subjects.

Making a large-scale change in the education naturally takes time. The situation for students in different municipalities, schools, and even classrooms will vary for many years before all teachers have had time to embrace digital competence and programming concepts as part of their everyday teaching. As the early experience from England indicates, sufficient financial support is not enough; what seems to be most important is access to continuous professional development of high quality, suitable material, and peer support. In addition, school leadership is of crucial importance, as teachers need time, access to professional development, and support to make the best of the new situation.

Professional development is a continuous process, where teachers learn from various sources and from each other. In the field of CS, the principles of life-long learning become increasingly important, as technology moves forward at a fast pace. Although the basic principles and ideas remain the same, new tools are introduced at a regular basis, and teachers need to be able to evaluate and select the right tool for their particular teaching situation.

The authors believe that the ongoing work on introducing programming and digital competence in the curriculum for Swedish basic education is a good start, although much still needs to be done. By presenting the new Swedish curriculum and the practical considerations surrounding its implementation, we hope to add 
to the discussion on how CS is being introduced in primary education throughout the world. We think that an international discussion on teaching CS in basic education is both important and valuable, both for sharing experiences and learning from each other.

\section{References}

1. A. Balanskat and K. Engelhardt. Computing our future. computer programming and coding. priorities, school curricula and initiatives across Europe, 2015.

2. K. Bateman. Computing teachers need more training, say students, January 2015.

3. Department for Education. National curriculum in England: Computing programmes of study, 2013. https://www.gov.uk/government/publications/nationalcurriculum-in-england-computing-programmes-of-study.

4. Digitaliseringskommissionen. En digital agenda i människans tjänst : en ljusnande framtid kan bli vår : delbetänkande. Technical Report SOU 2014:13, 2014.

5. European Commission. DigComp 2.0: The Digital Competence Framework for Citizens, 2016. Online, accessed April 22, 2017.

6. Finnish National Board of Education. Perusopetuksen opetussuunnitelman perusteet 2014, 2014.

7. F. Heintz, L. Mannila, and T. Frnqvist. A review of models for introducing computational thinking, computer science and computing in k-12 education. In 2016 IEEE Frontiers in Education Conference (FIE), pages 1-9, 2016.

8. F. Heintz, L. Mannila, K. Nygårds, P. Parnes, and B. Regnell. Computing at school in Sweden - experiences from introducing computer science within existing subjects. In Proc. ISSEP, 2015.

9. Informatics Europe and ACM Europe. Informatics in education: Europe cannot afford to miss the boat, 2015. Report of the joint Informatics Europe and ACM Europe Working Group on Informatics Education.

10. M. Johanssen and J. Nissen. It i framtidens samhälle och i dagens skola. Utbildning och demokrati, 10:103-132, 2001.

11. L. Rolandsson and I.-B. Skogh. Programming in school: Look back to move forward. Trans. Comput. Educ., 14(2):12:1-12:25, 2014.

12. Skolverket. Få syn på digitaliseringen på grundskolnivå, June 2017.

13. R. Swidenbank. Coding in British schools: A review of the first term, January 2015.

14. TeacherHack - En digitaliserad Lgr11. http://www.teacherhack.com/.

15. Utbildningsdepartementet. Skolfs 2017:11, 2017.

16. White House. Computer science for all, 2016. https://www.whitehouse.gov/blog/2016/01/30/computer-science-all.

17. J. Wing. Computational thinking. Comm. of the ACM, 49(3):33-35, 2006. 